\title{
Automated detection of snow avalanche deposits: segmentation and classification of optical remote sensing imagery
}

\author{
M. J. Lato ${ }^{1}$, R. Frauenfelder ${ }^{1}$, and Y. Bühler ${ }^{2}$ \\ ${ }^{1}$ Norwegian Geotechnical Institute, Pb. 3930 Ullevaal Stadion, 0806 Oslo, Norway \\ ${ }^{2}$ WSL Institute for Snow and Avalanche Research SLF, Flüelastrasse 11, 7260 Davos, Switzerland
}

Correspondence to: M. J. Lato (mjlato@gmail.com)

Received: 25 May 2012 - Revised: 6 August 2012 - Accepted: 20 August 2012 - Published: 13 September 2012

\begin{abstract}
Snow avalanches in mountainous areas pose a significant threat to infrastructure (roads, railways, energy transmission corridors), personal property (homes) and recreational areas as well as for lives of people living and moving in alpine terrain. The impacts of snow avalanches range from delays and financial loss through road and railway closures, destruction of property and infrastructure, to loss of life. Avalanche warnings today are mainly based on meteorological information, snow pack information, field observations, historically recorded avalanche events as well as experience and expert knowledge. The ability to automatically identify snow avalanches using Very High Resolution (VHR) optical remote sensing imagery has the potential to assist in the development of accurate, spatially widespread, detailed maps of zones prone to avalanches as well as to build up data bases of past avalanche events in poorly accessible regions. This would provide decision makers with improved knowledge of the frequency and size distributions of avalanches in such areas. We used an object-oriented image interpretation approach, which employs segmentation and classification methodologies, to detect recent snow avalanche deposits within VHR panchromatic optical remote sensing imagery. This produces avalanche deposit maps, which can be integrated with other spatial mapping and terrain data. The object-oriented approach has been tested and validated against manually generated maps in which avalanches are visually recognized and digitized. The accuracy (both users and producers) are over 0.9 with errors of commission less than 0.05 . Future research is directed to widespread testing of the algorithm on data generated by various sensors and improvement of the algorithm in high noise regions as well as the mapping of avalanche paths alongside their deposits.
\end{abstract}

\section{Avalanche hazards}

Mountainous countries, such as Switzerland, Norway and Canada, are annually subjected to natural hazards originating in alpine terrain. Such hazards include rockfall, landslide, debris flow, flash floods, snow and ice avalanches. The impacts of such hazards range from delays and financial loss through road and rail line closures, the destruction of property and infrastructure, to loss of life. Of these major geologically and meteorologically controlled natural hazards, snow avalanches have caused the greatest number of causalities in Norway during the last decades (Jaedicke et al., 2008). The same is reported from Switzerland for the period of 1997 2007 (Harvey and Zweifel, 2008). In the same time period, an estimated 1020 causalities have been reported as a direct result of snow avalanches in the entire European Alps and 250 per year worldwide (Schweizer, 2008). Specifically, 155 fatalities from snow avalanche accidents were reported in Canada during the period 1997-2007 (Jamieson et al., 2011).

Snow avalanches are the result of unstable masses of snow that detach from a mountain or hillside. Snow avalanches can occur in various meteorological situations, within variable terrain and can manifest themselves in many forms, the common division among avalanches being loose snow versus slab and wet versus dry snow avalanches. Also powder clouds can be the component of any dry moving avalanche. The natural release of an avalanche is typically dependant on parameters such as snowfall, temperature, wind direction and speed, snowpack conditions, slope orientation, terrain and vegetation (Armstrong and Armstrong, 1987; Gubler and Bader, 1989; McClung and Schaerer, 1993). Figure 1 portrays two dry snow avalanches, one naturally triggered avalanche deposit (a) and one artificially triggered at the Norwegian 

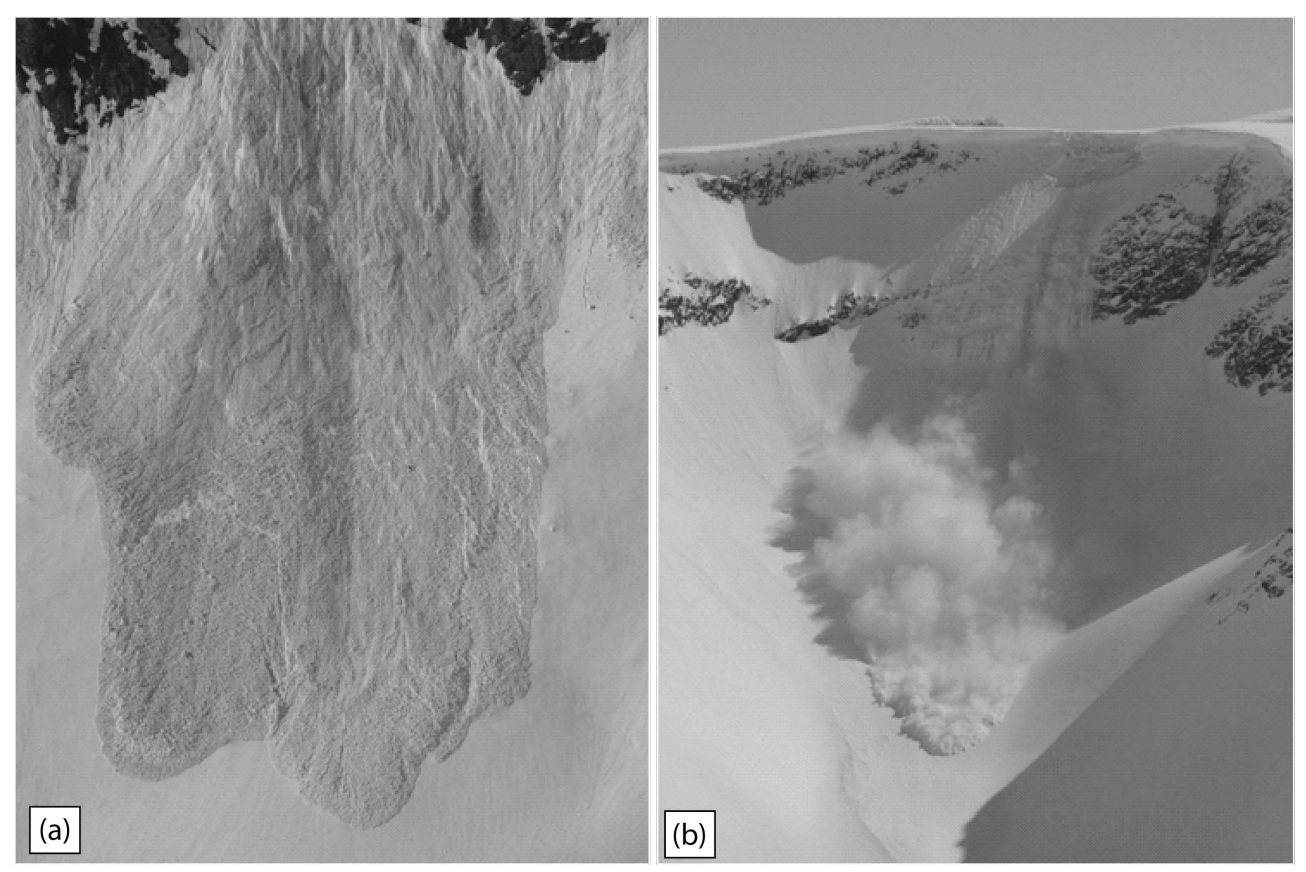

Fig. 1. Deposit of a naturally released snow avalanche (a); Artificially triggered avalanche in transit at NGI's research station at Ryggfonn (b). Both sites are located within the Strynefjell region, Sogn og Fjordane, Norway. Photos courtesy of: Krister Kristersen (a) and Hedda Breien (b), Norwegian Geotechnical Institute.

Geotechnical Institute's research station at Ryggfonn, Stryn, Western Norway (b).

\section{Need for more complete and precise avalanche data}

Snow avalanches, in general, are poorly mapped, which is commonly due to the remote location of their occurrence. Often avalanches are only reported if they cause an obstruction to public infrastructure, damage to personal property, or are witnessed and reported by local observers. However, decisions regarding, e.g., the closure of roads and rail lines and the setting of warning levels, rely on information that is derived from knowledge of historic events in combination with metrological data of the recent past and expected future (Bellaire et al., 2011).

The general practiced routine for mapping snow avalanches relies on two main techniques. The first technique involves a field mission to map the extent and location of avalanche start-zones and runout-zones by hand, by amateur photographs, or with a GPS device. These field missions are typically conducted during the peak avalanche period of the year as snow depth and layers are also recorded in the field. Problems related to this method are: poor accessibility of the terrain due to avalanche danger, only small areas can be surveyed, and surveys can only be conducted in good weather. The second commonly employed technique for mapping snow avalanches is the visual analysis and digitising of aerial photographs or optical remote-sensing imagery (Scott, 2009). Both methods require expert involvement and visual identification of a fallen snow avalanche.

The ability to automatically identify snow avalanches using Very High Resolution (VHR) optical imagery would greatly assist in the development of accurate, spatially widespread, detailed maps of zones historically prone to avalanches. Such maps could be used to estimate regional susceptibility. This would provide decision makers with knowledge of the frequency of avalanches as well as details regarding the size and extent of historical events. This increase in knowledge and access to data will have two pertinent applications: short-term forecasting and mitigation (e.g., road/railway closures, evacuations), and long-term planning (e.g., transport network planning, mitigation measure design, municipal planning). Forecasting, mitigation and planning are critical for maintaining public safety, and managing public developments into the future through the use of susceptibility modelling.

Another application is the use of such data in modelling: recently developed numerical avalanche simulation tools such as RAMMS (Christen et al., 2010), SAMOS (Sampl and Zwinger, 2004) or ELBA+ (Keiler et al., 2006) require accurate avalanche release and run-out information for calibration and validation of the models. 
Table 1. Selection of VHR spaceborne and airborne sensors potentially suited for snow avalanche mapping. Note: for space-borne sensors, only commercial ones are listed. Spatial resolution is given at nadir.

\begin{tabular}{|c|c|c|c|c|c|c|}
\hline \multirow[t]{2}{*}{ Sensor } & \multirow[t]{2}{*}{ Lifetime } & \multirow[t]{2}{*}{ Bands } & \multicolumn{2}{|c|}{ Spatial resolution (m) } & \multirow{2}{*}{$\begin{array}{l}\text { Swath } \\
(\mathrm{km})\end{array}$} & \multirow{2}{*}{$\begin{array}{l}\text { Revisit time } \\
\text { (days) }\end{array}$} \\
\hline & & & panchromatic & multi-spectral & & \\
\hline IKONOS & 1999- & $\mathrm{p}, \mathrm{b}, \mathrm{g}, \mathrm{r}, \mathrm{nir}$ & 0.8 & 3.6 & 11 & 3 \\
\hline QUICKBIRD & 2001- & $\mathrm{p}, \mathrm{b}, \mathrm{g}, \mathrm{r}, \mathrm{nir}$ & 0.6 & 2.4 & 16.5 & 1 to 3.5 \\
\hline GeoEye-1 & $2008-$ & $\mathrm{b}, \mathrm{g}, \mathrm{r}, \mathrm{nir}$ & 0.5 & 2 & 15.2 & 3 \\
\hline WorldView-1 & $2007-$ & $\mathrm{p}$ & 0.5 & - & 17.6 & 1 to 5 \\
\hline WorldView-2 & 2009- & $\mathrm{p}, 8 \mathrm{~ms}$ & 0.46 & 2 & 16.4 & 1 to 4 \\
\hline ORBVIEW-3 & 2003- & $\mathrm{p}, 4 \mathrm{~ms}$ & 1 & 4 & 8 & $<3$ \\
\hline SPOT 5 & & $\mathrm{p}, \mathrm{g}, \mathrm{r}, \mathrm{nir}$, swir & $2.5,5$ & 10 & 60 & 2 to 3 \\
\hline FORMOSAT-2 & 2004- & $\mathrm{p}, \mathrm{b}, \mathrm{g}, \mathrm{r}, \mathrm{nir}$ & 2 & 8 & 24 & daily \\
\hline KOMPSAT-2 & 2006- & $\mathrm{p}, \mathrm{b}, \mathrm{g}, \mathrm{r}, \mathrm{nir}$ & 1 & 4 & 15 & 2 to 3 \\
\hline KOMPSAT-3 & $2012-$ & $\mathrm{p}, \mathrm{b}, \mathrm{g}, \mathrm{r}, \mathrm{nir}$ & 0.7 & 2.8 & 15 & 2 to 3 \\
\hline Cartosat 2B & 2010 & $\mathrm{p}$ & 0.8 & - & 9.6 & 4 \\
\hline Pléiades 1 & 2011 & $\mathrm{p}, \mathrm{b}, \mathrm{g}, \mathrm{r}$, nir & 0.7 & 2.0 & 20 & daily \\
\hline Pléiades 2 & 2012 & $\mathrm{p}, \mathrm{b}, \mathrm{g}, \mathrm{r}, \mathrm{nir}$ & 0.7 & 2.0 & 20 & daily \\
\hline \multicolumn{7}{|l|}{ Airborne } \\
\hline \multicolumn{2}{|l|}{ Sensor } & \multicolumn{5}{|l|}{ Bands } \\
\hline \multicolumn{2}{|c|}{ Leica ADS40-SH52 } & \multicolumn{5}{|l|}{$\mathrm{p}, \mathrm{b}, \mathrm{g}, \mathrm{r}, \mathrm{nir}$} \\
\hline \multicolumn{2}{|c|}{ Vexcel Ultracam } & \multicolumn{5}{|l|}{$\mathrm{b}, \mathrm{g}, \mathrm{r}$, nir } \\
\hline \multicolumn{2}{|c|}{ DMC } & \multicolumn{5}{|l|}{$\mathrm{b}, \mathrm{g}, \mathrm{r}, \mathrm{nir}$} \\
\hline \multicolumn{2}{|c|}{ Optech ALT 3033 LiDAR } & - & & & & \\
\hline
\end{tabular}

\section{Remote-sensing instruments}

Recent developments in the field of imaging sensors and data processing techniques, through the 1990s and 2000s, have resulted in the use of remotely sensed data for various and diverse applications for hazard mapping. Advancements in data collection techniques are producing imagery at previously unprecedented and unimaginable spatial, spectral, radiometric and temporal resolution. The advantages of using remotely sensed data vary by topic, but generally include safer evaluation of unstable and/or inaccessible regions, high spatial resolution, spatially continuous and multi-temporal mapping capabilities (change detection) and automated processing possibilities. Disadvantages of the use of remotely sensed data are generally in relation to the lack of ground truth data available during an analysis and data acquisition costs. Recent publications in the academic literature include: landslide and rockfall evaluation (Mantovani et al., 1996; McKean and Roering, 2004; Lato et al., 2012), urban deformation modelling (Perissin and Wang, 2011), stratigraphic modelling (Bellian et al., 2005), flood mapping and modelling (Brivio, et al., 2002; Sanders, 2007). Table 1 outlines various satellite and airborne sensors with sufficient resolution for such analyses. This list does not represent an exhaustive compilation of sensors, simply commonly employed instruments.
Previous research regarding automated detection of avalanches deposits with the help of VHR optical data has been carried out and published by Bühler et al. (2009), Frauenfelder et al. (2010), Larsen et al. (2010), and Salberg et al. (2011). These methods rely on diverse input data and proprietary software algorithms. These publications produce results of variable success and repeatability. The primary goal of the study presented herein is to develop a complete solution for automated avalanche deposit detection relying only on optical panchromatic imagery data. The algorithm is designed to stand alone. This study only uses commercial off-the-shelf image analysis software with the future goal of an implementation in a regional or national snow avalanche mapping programme. Future research planned on this topic includes integration of supplementary data and historical records to increase the accuracy and efficiency of the algorithm through the reduction of input data.

\subsection{Sensors and data acquisition}

The images used in this study were collected from both airborne and spaceborne platforms. The spaceborne imagery has been collected by the QuickBird satellite, over Western Norway, as illustrated in Fig. 2a. The airborne platform has been collected by a fixed wing aircraft with a Leica ADS40SH52 imaging unit, the images have been collected over Davos, South-eastern Switzerland, as illustrated in Fig. 2 b. 

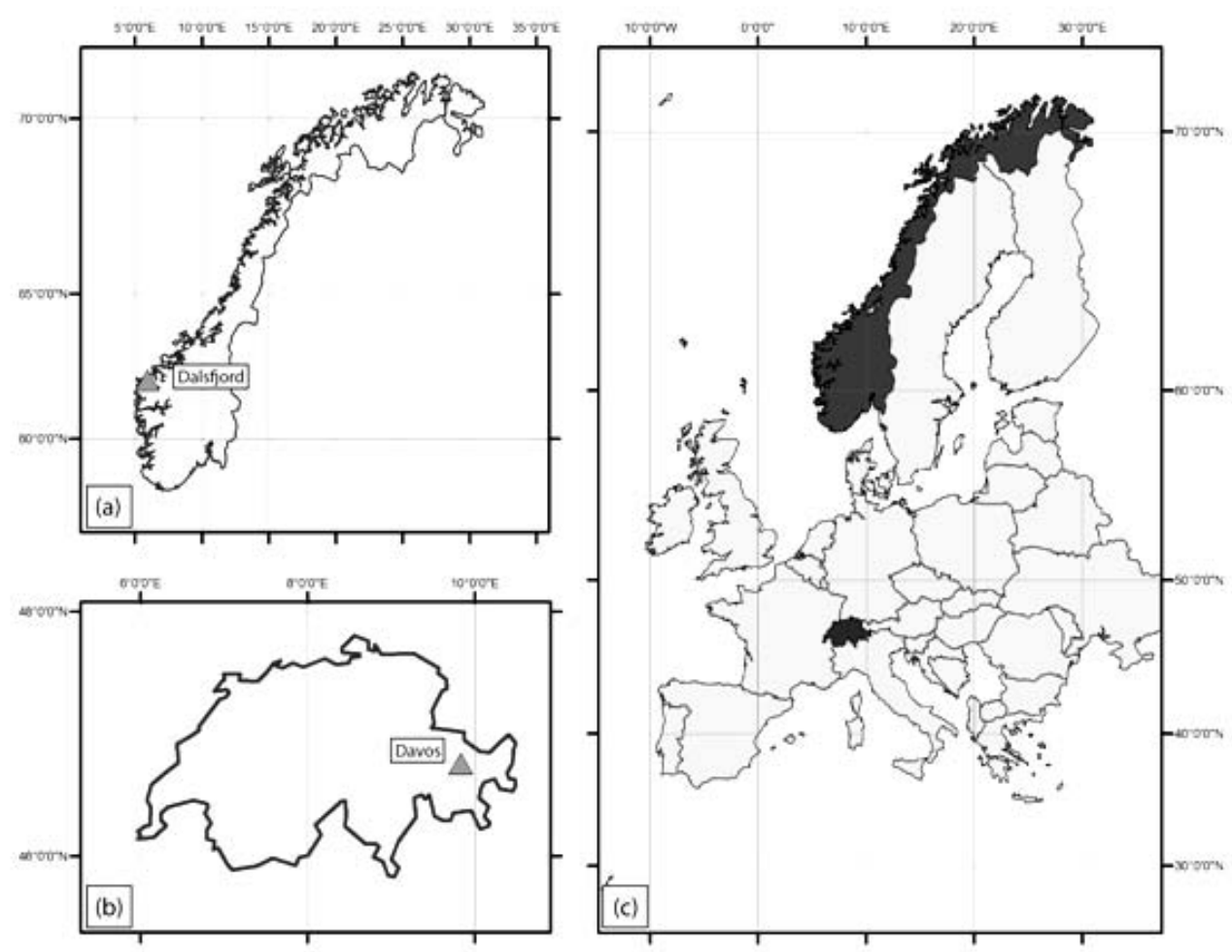

Fig. 2. Data collection sites depicted by grey triangles in (a) Norway and (b) Switzerland.

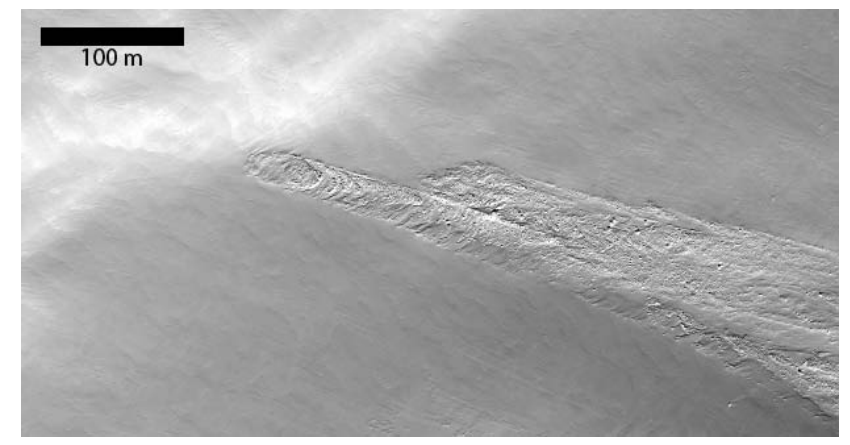

Fig. 3. Part of a single snow avalanche deposit in the Davos region of Switzerland. Image acquired with a Leica ADS40-SH52 optoelectronic pushbroom scanner. (Flow direction is from the lower right to the centre of the image).

All images used in this research project have been processed using only the panchromatic band.

\subsubsection{Leica ADS40-SH52}

The Leica ADS40-SH52 is a multi-band (near-infrared, red, green, blue, panchromatic), 12-bit opto-electronic pushbroom scanner. The resultant imagery is co-registered across the five bands; this eliminates distortion and error between the images (Leica, 2008). The images were collected with the ADS40-SH52 mounted on a Pilatus Porter PC6 aircraft in the Davos Valley on 26 April 2008. This data acquisition was carried out for the study of Bühler et al. (2009). The survey covered a region approximately $6 \mathrm{~km}$ by $15 \mathrm{~km}$. The mission was flown at an average altitude of $2 \mathrm{~km}$ above ground surface; resultant imagery has a multi-spectral pixel resolution of $0.25 \mathrm{~m}$. The area is located approximately $1500 \mathrm{~m}$ above sea level (a.s.l.) with surrounding mountain peaks reaching altitudes of $2700 \mathrm{~m}$ a.s.1.

\subsubsection{QuickBird}

The QuickBird satellite is a multi-band (near-infrared, red, green, blue, panchromatic), 11-bit digital sensor. The satellite was launched on 18 October 2001 by DigitalGlobe, at an orbit of $482 \mathrm{~km}$; in October 2011 its orbit was lowered to $450 \mathrm{~km}$. The satellite is characterised by its $16.5 \mathrm{~km}$ wide swath, high contrast sensors and high signal-to-noise ratio. The QuickBird imagery used in this research project were collected over Western Norway, a rugged area that is topographically dominated by the Caledonian mountain range. The QuickBird imagery has a multi-spectral pixel resolution of 2.44-2.88 m and a panchromatic pixel resolution of 0.61$0.72 \mathrm{~m}$ (DigitalGlobe, 2000). 


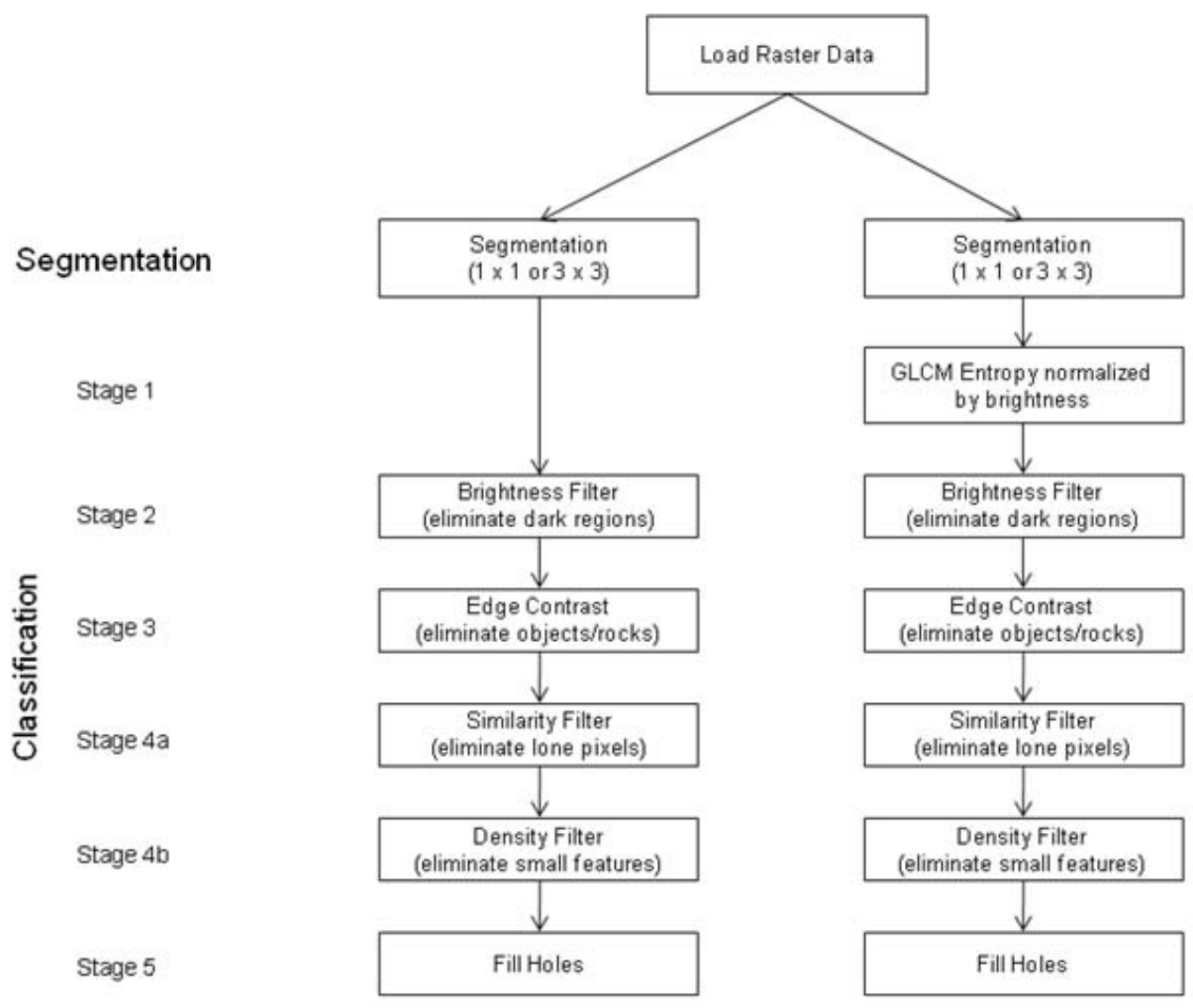

Fig. 4. eCognition workflow steps for the identification of avalanche signatures from VHR optical satellite imagery. Note the slight variation in methodology when using Leica ADS40-SH52 imagery (left workflow) versus QuickBird imagery (right workflow).

\section{Methodology: algorithm development}

The prerequisite in the development of the algorithm was that it be stable, repeatable and logical, i.e., avoiding the use of "black box" algorithms. The method researched and developed for this paper represents an approach to mapping snow avalanche deposits in which the only information required is the orthorectified imagery. The algorithms employ object based image analysis techniques. The development of the classification algorithms was done using an iterative approach with successive refinement of the input variables. In effect, hundreds of independent variables were tested, as well as the order and combination of variables. The algorithm development was done based on a methodical trial and error process. The development was done by using small sections of larger images, this was necessary to accommodate the large number of iterative developments in the formulation of the algorithm.

\subsection{Image analysis}

One characteristic of snow avalanches is that they are relatively easy to visually distinguish in a panchromatic image, provided the image is uniformly exposed. As illustrated in
Fig. 3, the snow avalanche is readily identifiable, even to a non-expert. However, although the avalanche is easily identifiable, there are regions within the avalanche deposit that are indistinguishable from fresh undisturbed snow.

From an image interpretation perspective, the target the snow avalanche runout-zone deposit - is distinguishable based on its signature with respect to the rest of the image as a whole, not just its surrounding pixels. Thus, for an automated snow avalanche detection algorithm to be successful, it must be capable of an image interpretation that looks at the neighbourhood of pixels in comparison to the rest of the image, not simply at individual pixels in isolation.

The desire to be able to assess the image as a whole while evaluating the neighbourhood of pixels led to the use of hierarchical object-oriented image classification tools. The use of hierarchical object-oriented image analysis tools are designed to use similar cognitive reasoning as the human mind, which employs segmentation and classification methodologies (Benz et al., 2004; Willhauck, 2000). Research presented in this paper is done using the software package eCognition, Version 8 (Definiens, 2011). The eCognition software has the ability to use both spatial and spectral information when conducting the image classification, making it an ideal 

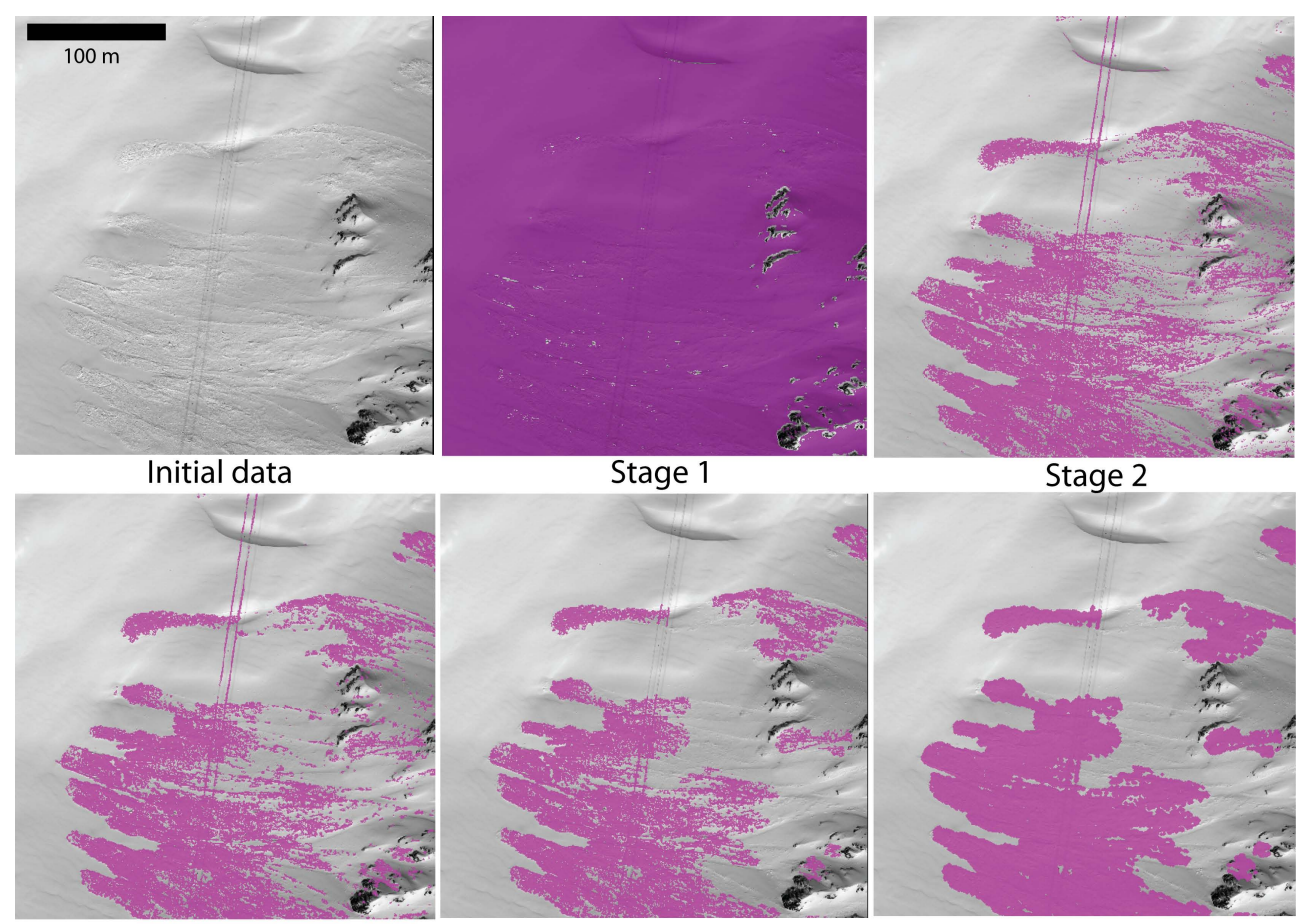

Stage 1

Stage 2

Stage 3

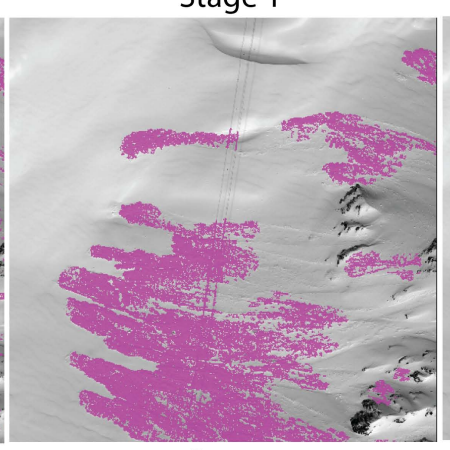

Stage 4

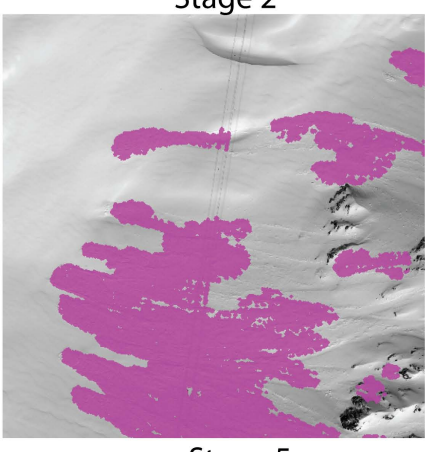

Stage 5

Fig. 5. General processing steps and staged results for avalanche deposit identification in eCognition. The process illustrates the workflow for Leica imagery as reported in Fig. 4. The steps illustrate the progressive segmentation and classification of the image, resulting in an image with only avalanche deposits identified.

candidate for automated detection of snow avalanches from VHR optical imagery.

Object-oriented image classification differs from pixel based classification in that the assignment of membership is done using soft classifiers that employ fuzzy logic (Benz et al., 2004). The requirement for membership does not require complete agreement between the data and the classifier, rather a value between zero and one is calculated, in which zero represents improbability of agreement and one represents complete agreement. An excellent overview of image classification techniques and the advantages of objectoriented classification have been published by Yam (2003).

Unlike previously published research, the results presented below are based exclusively on the segmentation and classification of information visible in the optical imagery. Information derived from digital terrain models with respect to slope and aspect are not considered; neither are vegetation masks or other masking tools/layers utilised. The reason for limiting the input data to only the optical imagery is to test the ability of the object-oriented image processing algorithms within eCognition.

\subsubsection{Data processing}

The image-processing workflow developed in eCognition for the automated identification of snow avalanches relies on six different variable types, as identified in Table 2 . The process is sequential and the order of segmentation and classification of the image is critical to the success and efficiency of the algorithm. The two different imaging sources, Leica ADS40 and QuickBird, require a slightly different implementation of the variables, as illustrated in Fig. 4 and Table 2.

The variables used in the algorithm act as logical gates, as illustrated in Fig. 4. The successive gates progressively classify the image; each step eliminates regions of the image that are not representative of avalanches. The processing workflow is optimised so that if a pixel fails to meet the requirements of a certain logical gate, it is excluded from all future processing steps. This ensures a time efficient processing chain while exploiting the nature of the software to compare pixel neighbourhoods within the entire image. The fuzzy logic employed by object-oriented image classification allows the user to easily changing the classifiers to accommodate irregularities in the image. This is important when working with images that have variable illumination, such as regions in the sun and shade.

Four of the six variables used in the process described herein are standard image processing variables: brightness, contrast, similarity and neighbour distance. The other two variables, grey level co-occurrence matrix (GLCM) entropy and GLCM dissimilarity, use information with respect to the texture of the image as defined by Haralick et al. (1973) and Haralick (1979). 
Table 2. Variables used in algorithm developed in eCognition for the automated detection and 249 mapping of snow avalanches in VHR panchromatic imagery. (*Variable only used on QuickBird 250 imagery).

\begin{tabular}{ll}
\hline Variable & Purpose \\
\hline GLCM Entropy ${ }^{*}$ & Eliminate regions with a high level of order \\
GLCM Dissimilarity & Eliminate regions with minimal contrast to surrounding pixels (e.g., fresh snow) \\
Brightness & Eliminate dark pixels (e.g., trees, rocks) \\
Contrast & Eliminate sharp boundaries (snow beside a rock) \\
Similarity & Eliminate small groupings of pixels that are too small to represent an avalanche \\
Neighbour distance & Fill in small gaps surrounded by known avalanche pixels \\
\hline
\end{tabular}

The GLCM assess how frequently different combinations of pixels, containing different levels of grey, appear within an image. The two GLCM variables used in the automated detection algorithm are dissimilarity and entropy. GLCM entropy is a measure of the randomness/disorder and intensity of the grey value distribution. The entropy values are maximized when the distribution of the magnitude of the grey level values are low, and small when the distribution of the grey level values are random (Partio et al., 2002). The GLCM dissimilarity variable is a measure of the contrast of an individual pixel from its neighbouring pixels. The value increases linearly, as opposed to exponentially like GLCM contrast; the dissimilarity value will be high if the local region has a high degree of variation (Cleve et al., 2008; Hall-Beyer, 2007).

Due to the variable amount of shadowing encountered when processing QuickBird data, which is due to the time of year, time of day and geographic location of the data collection (Fig. 2a), an additional processing step is added. This step, identified in Fig. 4 as "GLCM Entropy normalised by brightness" enables local shadowing/brightness to be removed and only the relative GLCM matrix to be processed. This process is not needed with the Lieca data due to the lack of shadows in the images.

A visual example of the processing chain is illustrated in Fig. 5. At the first step the algorithm assumes that each pixel in the image has the possibility of representing avalanche snow. As the image is processed through various steps, pixels are eliminated as being not representative of avalanche snow. The final step selects only those pixels that pass each gate and are, therefore, considered to be representative of a snow avalanche deposit.

\section{Results: validation of algorithm}

In the following, we illustrate four examples of the implementation of the automated detection algorithm using eCognition, with visualisation in ArcGIS. The first two examples are conducted on Leica ADS40-SH52 imagery, while the second two examples use QuickBird imagery. As presented in this paper, only entire scenes from the Leica imagery are used for statistical analysis. The scenes presented in the following section are the only scenes tested to date.

To facilitate the testing and validation of the algorithm an independent avalanche expert, with a background in remotesensing and avalanche research, conducted the manually mapping and digitising of snow avalanches visible in the imagery used in for this research. The instructions were to identify all visible snow avalanches greater than three metres in width and to digitise their outlines. The researcher was only allowed to use information visible in the optical imagery. Tree masks, digital elevation, slope or aspect models were not used to aid in the classification and the digitising process. The work was subsequently checked by another avalanche expert, prior to comparison with the outlines generated by the automated detection approach.

\subsection{Validation and accuracy assessments}

The imagery and analyses reported below represent images that were only used for validation, not for the development of the algorithm. Over fifteen different scenes and images were used in the development, some of which contained sections of the images below. The algorithm development did not involve comparison of the automatically detected avalanches to the manually mapped avalanches; this comparison was only completed as a final comparative test and is presented in this paper. As no ground truth data is available, the manual digitising completed by the avalanche expert is used as the "truth" for accuracy evaluations. This is acceptable as visual identification from imagery is the state-of-practise method for avalanche deposit mapping. The first two examples are large scenes from the Davos region in Switzerland in which land classification statistics can be evaluated.

The accuracy measures calculated in the following examples are: Kappa, Users Accuracy and Producers Accuracy (Foody, 2002; Congalton and Green, 1999). Kappa is the measure of the improvement in the tested classification method versus a random classification. A Kappa value near zero indicates the classification method is no better than a random classification, where values near one indicate excellent agreement between the classified data and the ground truth data. The Users Accuracy is the ratio between the area correctly identified as avalanche versus the total area 
Table 3. Accuracy of the avalanche classification algorithm versus the manual digitizing methods.

\begin{tabular}{llllll}
\hline Dataset & Kappa (no buffer) & Users Accuracy & Producers Accuracy & Commission Error & Omission Error \\
\hline Town of Davos (\#1) & 0.890 & 0.914 & 0.900 & 0.1 & 0.086 \\
Davos Ski Resort (\#2) & 0.900 & 0.905 & 0.910 & 0.09 & 0.015 \\
\hline
\end{tabular}

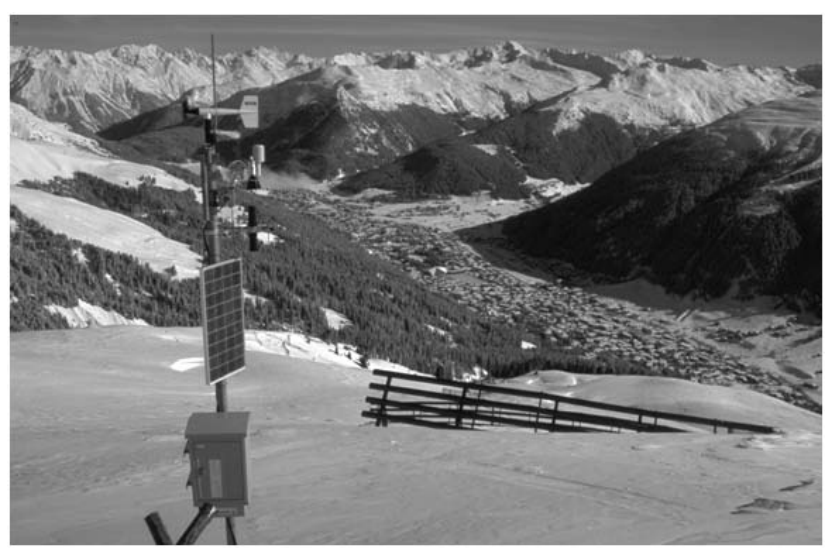

Fig. 6. View from Davos-Parsenn down to the town of Davos, Switzerland (Photo courtesy of: Jürg Schweizer, SLF).

classified as avalanche; while the Producers Accuracy is a measure of the ratio between the area automatically classified as avalanche versus the area manually classified as avalanche. The results of the analysis are reported in Table 3. Users and Producers accuracy can be directly used to calculate errors of commission and omission. These measures are only calculated on datasets in which the entire scene was tested - which, in this paper, are the Leica scenes.

\subsection{Leica: Town of Davos}

The town of Davos (Fig. 6), located in Eastern Switzerland, is considerably rugged and subject to a high frequency of small to large scale avalanches on an annual basis. The region, illustrated in Fig. 7, is roughly $1700 \mathrm{~m}$ by $1400 \mathrm{~m}$ (2.4 million $\left.\mathrm{m}^{2}\right)$, and comprises of numerous avalanches varying in size from less than five metres wide to over one hundred metres wide. The automated detection algorithm executed on this image is identified as in the left side workflow of Fig. 4. The raw size of the analysed image section (shown in Fig. 7) is approximately 38 million pixels. Due to processing restrictions of the eCognition software package, the image was subsampled before processing. Using a $3 \times 3$ classification matrix, thereby subsampling the data from $0.25 \mathrm{~m}$ to $0.75 \mathrm{~m}$, the number of pixels to be processed was decreased by $88 \%$, resulting in approximately 4.2 million pixels.

The manual mapping and digitising of snow avalanches through visual analysis resulted in the identification of 35 non-connected and non-overlapping snow avalanche regions. Through a discrete analysis of the regions classified by the

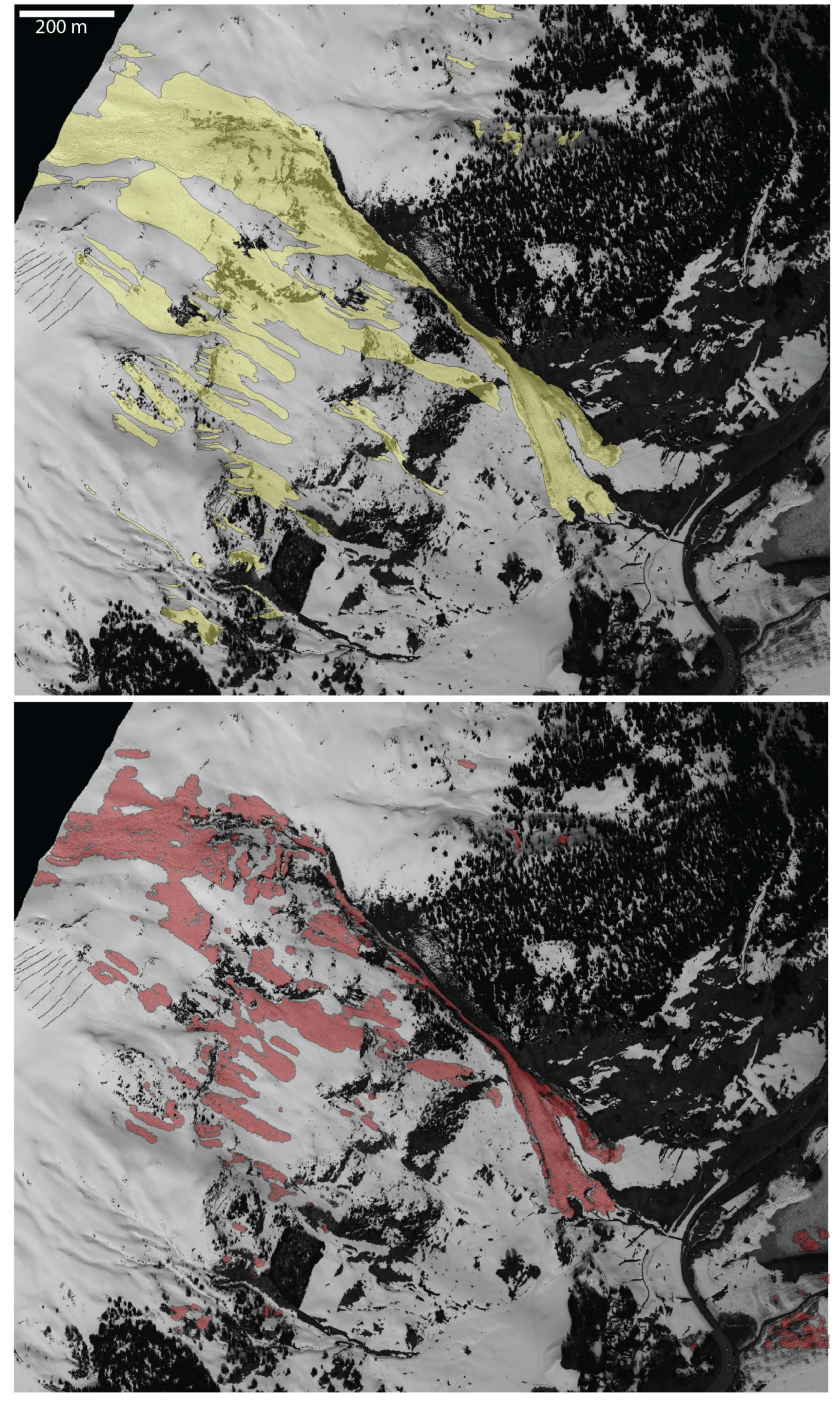

Fig. 7. Leica panchromatic imagery collected near the town of Davos. The primary target of this image is the Salezer Avalanche (March, 2008). Image (a) (above) illustrates manual mapping of snow avalanche deposits in ArcGIS, while image (b) (below) is processed automatically in eCognition and then visualised in ArcGIS.

automated algorithm versus those that are manually mapped, 33 of the 35 manually mapped snow avalanches are correctly identified by the automated algorithm. Both of the snow avalanche runout deposits not detected by the automated approach are very small deposits and have undergone partial 
melting. As well, the automated mapping algorithm correctly identified one smaller avalanche runout deposit that was overlooked by the human observer. The results presented herein are more comprehensive than those presented by Bühler et al. (2009) as the object oriented approach is able to identify smaller objects and "dirty" snow as part of the avalanche whereas previous methods have failed.

The automated mapping approach characterised $201667 \mathrm{~m}^{2}$ of the image as being representative of a snow avalanche deposit, roughly $8.5 \%$ of the image. Through a spatial intersection between the manually mapped avalanches and the automatically mapped avalanches, $184432 \mathrm{~m}^{2}$, or $89 \%$, of the automatically mapped regions are spatially overlapping with the manually mapped regions. Allowing for a $5 \mathrm{~m}$ buffer to account for digitising and translation errors the spatial intersection increases to $192803 \mathrm{~m}^{2}$, or $95 \%$.

\subsection{Leica: Davos-Parsenn Ski Resort}

The Davos-Parsenn Ski Resort, located near the town of Davos is subject to a high annual frequency of avalanches; a large number of them are artificially triggered to secure the ski slopes. Due to the difficulties in accessibility, and dangers associated with field mapping, the identification of snow avalanches is best suited by remote evaluation. The region illustrated in Fig. 8 is roughly $1700 \mathrm{~m}$ by $900 \mathrm{~m}$; the image consists of numerous avalanches varying in size from less than five metres wide to over fifty metres in width. The automated detection algorithm executed on this image is identified as in the left side workflow of Fig. 4. The raw size of this image section (Fig. 8) is approximately 20 million pixels. Due to processing restrictions of the eCognition software package, also this image had to be subsampled before processing. Using a $3 \times 3$ classification matrix, the number of pixels to be processed was decreased by $88 \%$, resulting in approximately 1.8 million pixels. As presented in the above section, a similar segmentation and classification analysis has been conducted on the image.

The manual mapping and digitising of snow avalanches through visual analysis resulted in the identification of 21 non-connected and non-overlapping regions. Through a discrete analysis of the regions classified by the automated algorithm versus those that are manually mapped, 20 of the 21 manually mapped slides are correctly identified by the automated algorithm. The single avalanche, not detected by the automated approach, is characterised by a narrow track and has undergone significant melting, thus, making it visually similar in appearance to non-avalanche wet/ablated snow. As well, the automated mapping algorithm correctly identified two small avalanches that were overlooked by the human.

The automated mapping approach characterised $154000 \mathrm{~m}^{2}$ of the image as being representative of a fresh snow avalanche, roughly $10 \%$ of the image. Through a spatial intersection between the manually mapped avalanches

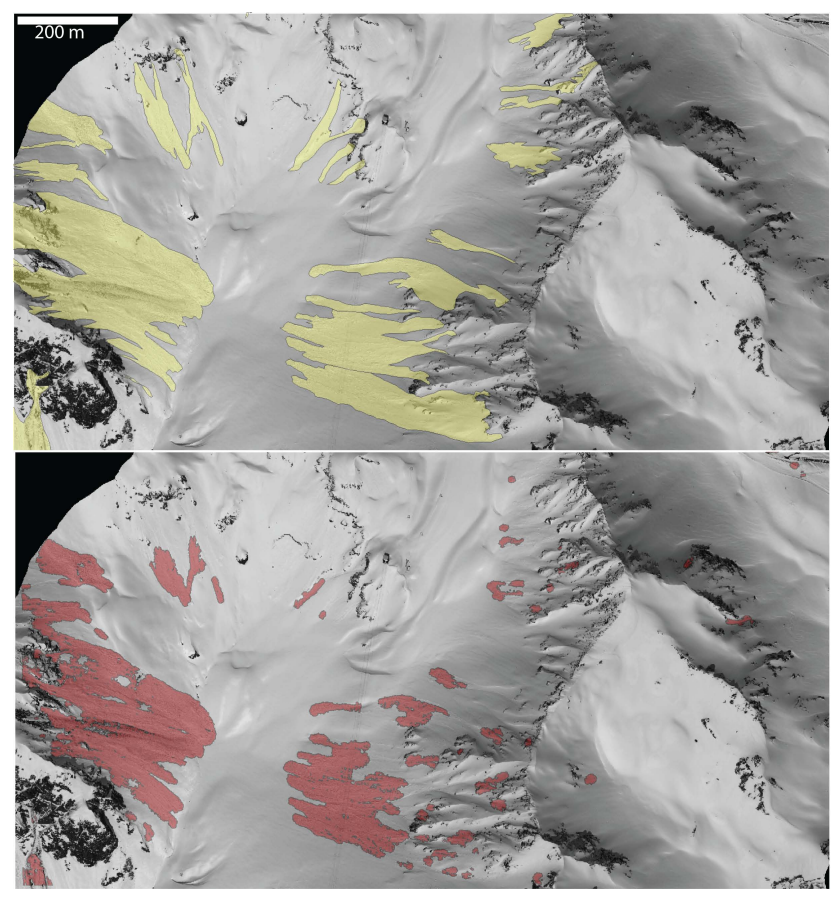

Fig. 8. Leica panchromatic imagery collected near the DavosParsenn ski resort. Image (a) (above) illustrates manual mapping of snow avalanches in ArcGIS, while image (b) (below) is processed automatically in eCognition and then visualised in ArcGIS.

and the automatically mapped avalanches, $140140 \mathrm{~m}^{2}$, or $91 \%$, of the automatically mapped regions are spatially linked to the manually mapped regions. Allowing for a $5 \mathrm{~m}$ buffer to account for digitising and translation errors, the spatial intersection increases to $149996 \mathrm{~m}^{2}$ or $97 \%$. Notably, the algorithms are able to distinguish avalanche snow from rock boulders, coniferous trees, tire tracks, as well as gondola cables.

\subsection{QuickBird: Dalsfjord Valley}

The Dalsfjorden valley (Møre and Romsdal county) in Western Norway is characterised by steep fjords surrounded by rugged mountain tops.

Two regions within Dalsdalen, a side-valley of the Dalsfjorden valley, have been mapped for snow avalanches by both manual and automated methods; the results are presented below.

Due to the low solar angle at high latitudes during winter time, the QuickBird imagery was subject to strong variation in illumination (unlike the Leica imagery). This results in over and under exposure throughout a single scene. When manually digitising the visible snow avalanches often regions in the shade are missed by the observer. This is due to the lack of pixel depth within the region, resulting in a smaller contrast difference between surrounding pixels and regions. Conversely, the automated method can compensate for this 


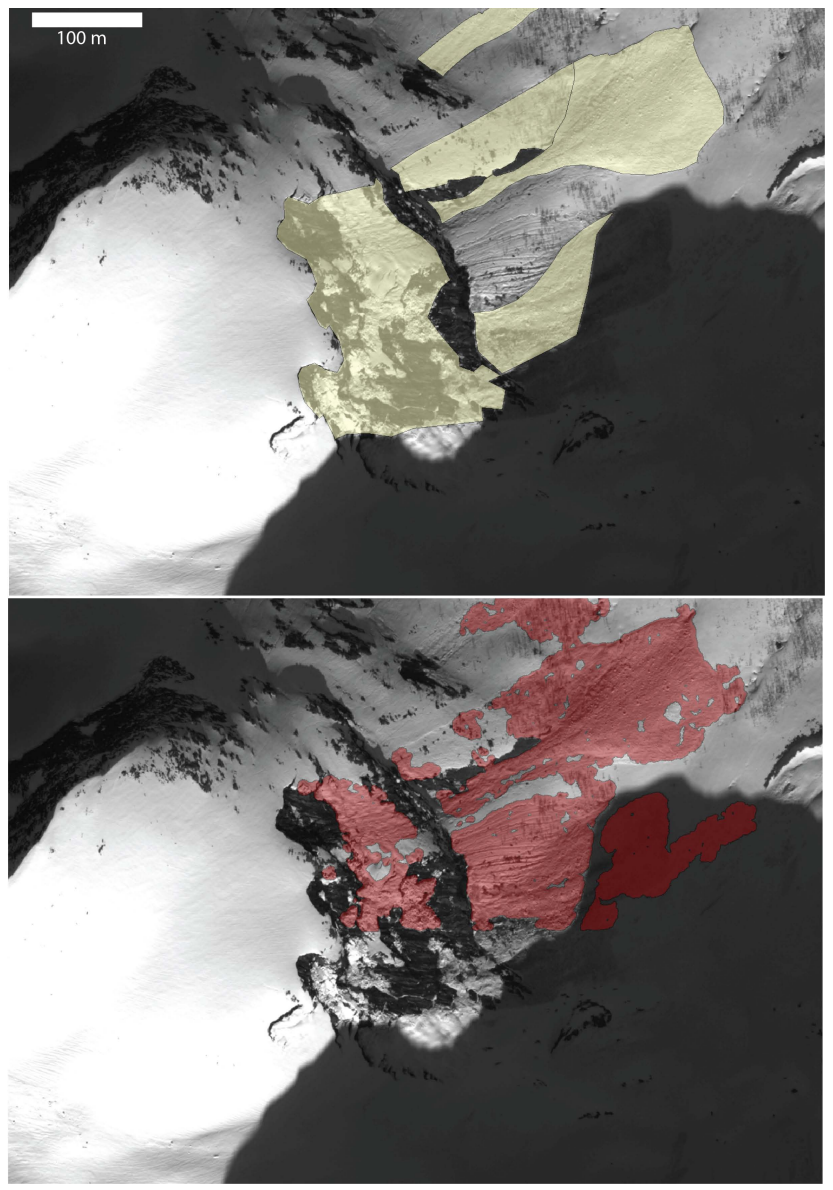

Fig. 9. Identification of snow avalanches in the Dalsfjord region through manual digitising (a, above) and automated digitising (b, below) methods.

situation and readily identify snow avalanches in the shade. Although the avalanches in the shade are visible to a human, when a large scene is mapped often small details are overlooked. This is a significant challenge with many remotesensing techniques. The following two examples illustrate the capability of the automated algorithm at a localised scale, specifically in regions containing variable exposure.

The first scene is a region approximately $900 \mathrm{~m}$ by $600 \mathrm{~m}$. The manual mapping method identified one large snow avalanche start-zone (centre of image) and one smaller one (upper image area) with two, respectively, one independent and non-overlapping deposits, as illustrated in Fig. 9a. There are bare areas between the start-zones and the runoutzone (outcropping rocks); those were not mapped. Also, one avalanche runout deposit in the shadow was not completed by manual mapping because - even though the observer knew that the deposit continued - its entire extent was not visible to the eye. The automated approach (Fig. 9b) correctly identified each of these avalanches, as well as the complete deposit area located in the shade.
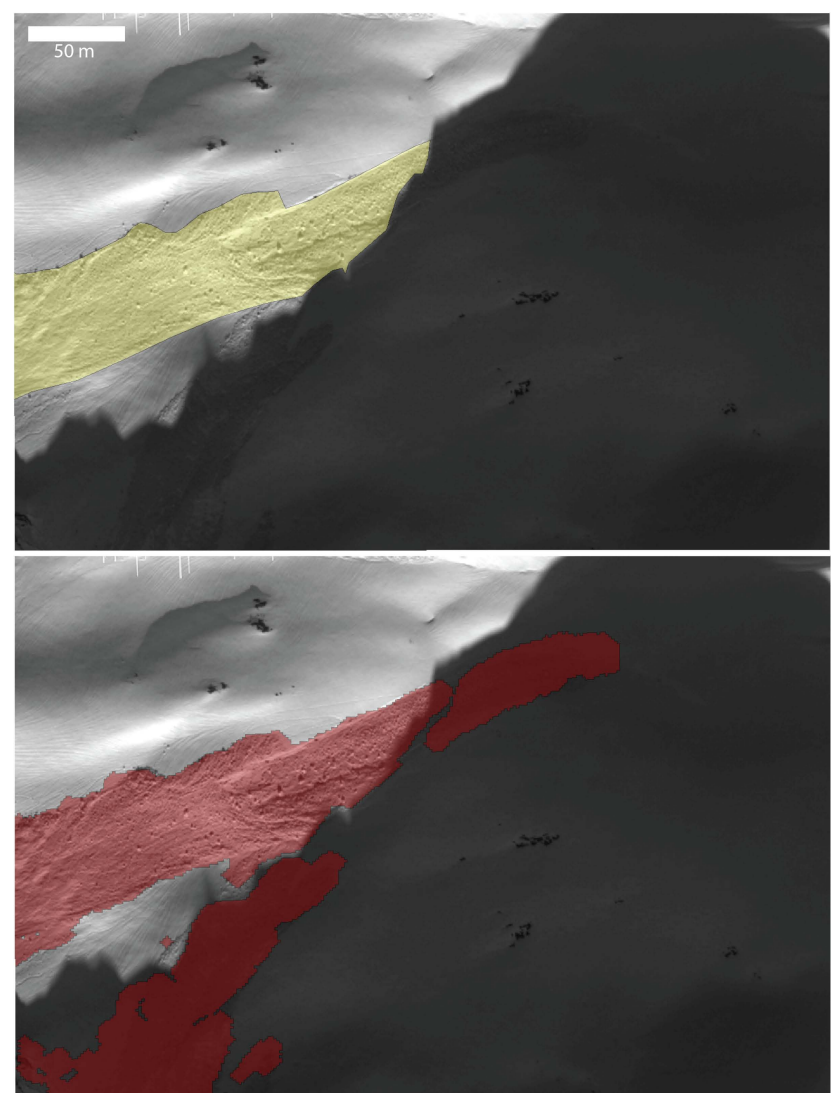

Fig. 10. QuickBird imagery over the Dalsfjord region. Image (a) (above) illustrates manual mapping of fresh snow avalanches in ArcGIS, while image (b) (below) is processed automatically in eCognition.

A second scene from the Dalsdalen valley, a zoomed in section of a single avalanche, illustrates the capability of the automated approach to clearly define the avalanche deposit in both fully illuminated and shady regions of an image. Figure 10a illustrates the manually digitised avalanche outline. Again, even though the observer knew that the deposit continued within the shade, it was not mapped since its entire extent was not easily visible by eye. Figure 10b illustrates the same image after processing by the automated detection algorithm. The capability of the automated algorithm is twofold: firstly it is able to replicate the analysis conducted by the human, and secondly it is capable of seeing information in regions that are commonly non-interpretable by the human eye.

\section{Discussion}

The methods illustrated in this paper demonstrate the ability to automatically detect snow avalanche deposits in optical imagery using object oriented image processing techniques. The results indicate an equal rate of omission and 

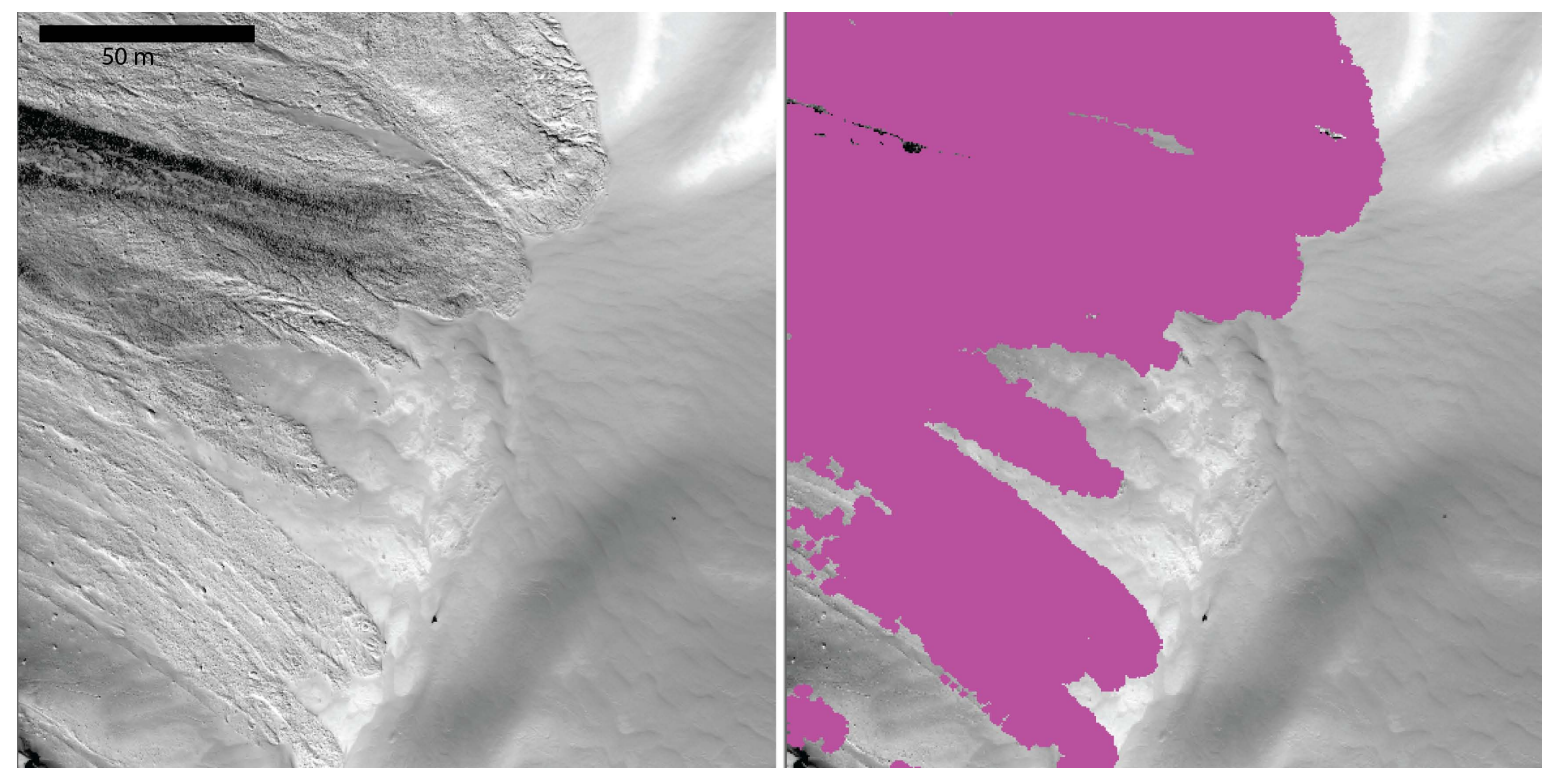

Fig. 11. Raw image (a, left) overlain by automatically identified avalanches (b, right) for a simple scene that does not contain noise or regions characterised by large tonal changes.
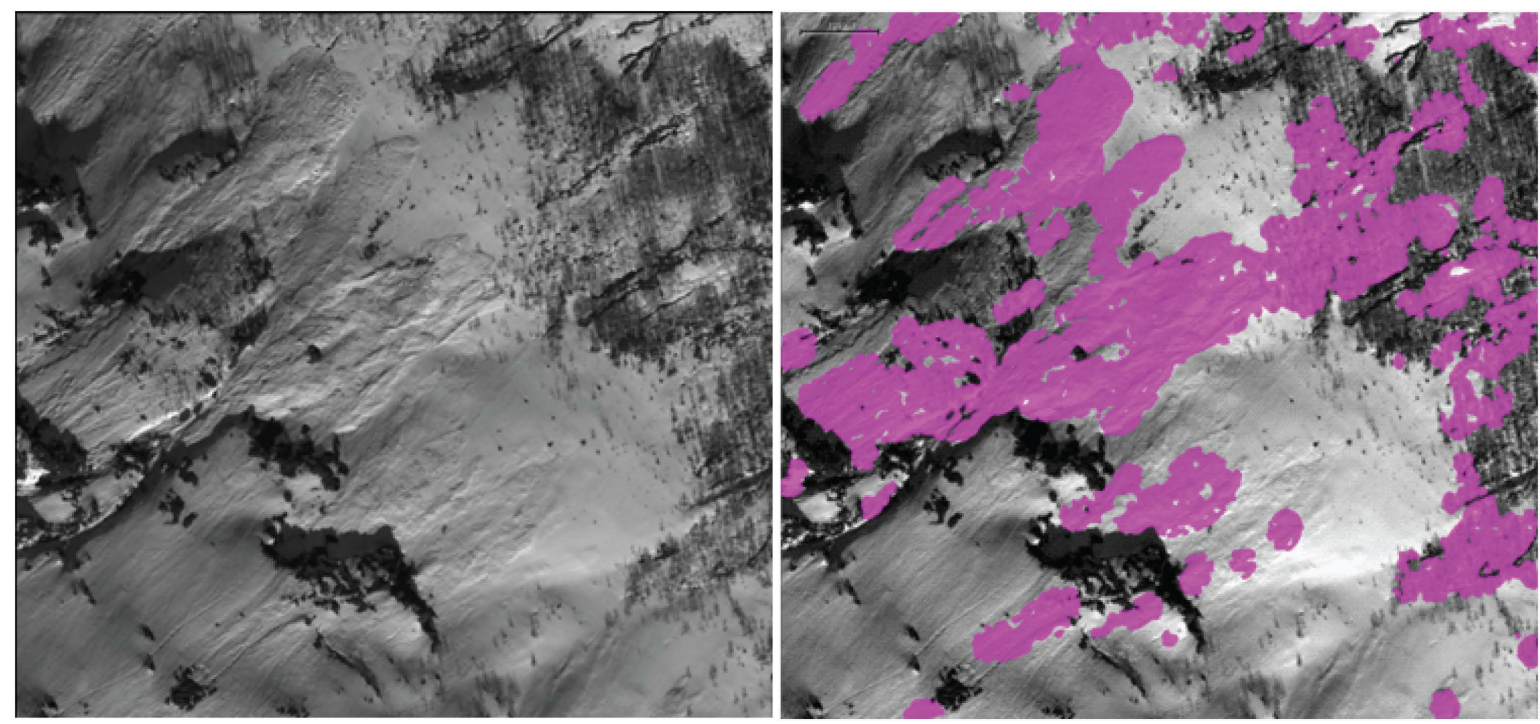

Fig. 12. QuickBird imagery over the Dalsfjord region, raw image (a) overlain by automatically identified avalanches (b). The avalanches in the right-hand image are correctly identified; however, regions of the image characterised by snow and sparse deciduous trees are falsely identified as avalanches as well.

errors of commission. Of note, the algorithms are able to distinguish avalanche snow from rock boulders, coniferous trees, tire tracks, as well as gondola cables. The workflows are designed to detect all types of snow avalanches.

The algorithm developed is, however, sensitive to the noise within the image. If the image consists of only smooth snow and avalanches, the algorithm will perform as desired, as the only regions in the image that display visible texture due to tonal variations will be avalanche deposits. As illustrated in Figure 11a, the image is comprised of smooth snow surfaces and numerous avalanche deposits. Figure $11 \mathrm{~b}$ illustrates the avalanches as identified by the automated detection algorithm.

One area in which the detection algorithm fails is distinguishing between avalanche material and deciduous trees without leaves. These areas are characterised by the algorithm as having a high level of disorder and, therefore, a high entropy value. Thus, it reduces the effectiveness of the GLCM logic gates, as these areas are detected as snow avalanches by the algorithm. Although many sensitivity tests 
were conducted, there is still a significant amount of uncertainty when such conditions are present in the imagery. An example of this situation is illustrated in Fig. 12; the regions of sparse deciduous trees are identified as avalanche material. Although the true avalanches are properly identified, the elimination of false avalanches needs to improve before the algorithm is implemented in such terrain.

One tool that this research does not take into account is the ability to apply a pre-classification filter to the optical images based on the probability of the terrain for an avalanche. For example, the classification of regions too flat or too steep to facilitate a snow avalanche, or regions with dense tree coverage, can be masked from subsequent avalanche identification analyses (Bühler et al., 2009). Future research will include a tighter integration with ArcGIS, involving the masking of images based on terrain features. Very high spatial resolution digital terrain models in alpine regions can be generated using airborne digital photogrammetry (Bühler et al., 2012) or airborne and terrestrial lidar sensors (Fischer et al., 2011). This should provide clearer results with fewer errors of commission. As well, eliminating regions within images based on pre-classification techniques will increase processing speed within eCognition through the reduction of input data.

To fully document the capability of the automated mapping approach, it must be compared with ground truth data, not just data mapped by a human observer. Since the human observer, as demonstrated above, is also capable of errors.

The asymmetry of errors, or omission versus commission errors, is critical for the development of a new landclassification algorithm. The discussions being are false positives (errors of commission) and false negatives (errors of omission) equally negative to a mapping programme. Would a decision maker rather know that all avalanches have been mapped, and some might be falsely done so, or that regions might be prone to avalanches that are not identified in the database? A high number of false positives can result in lost public space, or increased road closures; while a high number of false negatives can lead to increased accidents and a false sense of public security. The weighting of these values can only be assigned through discussion with decision and policy makers in consultation with those responsible for designing the detection algorithm. These are the larger philosophical questions to be addressed in future research on this topic with decision makers and policy planners.

\section{Conclusions}

The results presented in this paper illustrate the powerful capability of hierarchical object-oriented image processing available through eCognition in the automated detection of snow avalanche deposits from VHR optical imagery. The ability of the software to be programmed in a manner that mimics a human cognitive process is ideal for automated avalanche deposit detection as the characteristics that make a snow avalanche identifiable can be 'taught' to the programme and rapidly tested. The automated mapping of snow avalanches has been widely researched and sought after as a valuable tool in the development of forecasting models and for the development of hazard maps based on past events.

Our initial results exhibit the capability and potential use of hierarchical object-oriented image processing for the automated detection of snow avalanches from VHR optical imagery and support findings of previous investigations. The methods presented in this paper provide a number of advantages over traditional digitising techniques, these include: (1) a greater ability to detect avalanches in the shade, (2) the efficiency of the process, and (3) the ability to analyse multiple images in parallel, as the processing capabilities can be maximised to the extent of the computational resources available. With respect to the quality of the input imagery, pixel resolution and image exposure are the two most important variables to be considered when planning image acquisition.

The methods described and illustrated above are flexible and easily adapted for different sensors and image quality, but they require further testing and validation before implementation in an operational setting. Future research will focus on the following issues: (a) include test data from various space-borne sensors; (b) perform research on the distinction between dry and wet snow avalanches, as well as loose snow versus slab avalanches from the optical imagery; (c) automated detection and mapping of avalanche start-zones; (d) make use of masking layers and terrain information in order to increase the efficiency, reliability and accuracy of the models developed. The inclusion of such data will require a research team with diverse skills, including geographic and computational expertise.

Acknowledgements. The authors would like to thank Ruediger Wagner and Jacques Markram from Leica Geosystems AG for access to the Davos imagery. We are also grateful to the ESA project "avalRS" (ESRIN/Contract No. 22139(08/I-EC) through which the QuickBird data was made available to us. Gerry Baber and Dave Gauthier at Queen's University are acknowledged for their time in discussions regarding spatial statistics and snow avalanches in the Rocky Mountains. This research has been generously funded by the Norwegian Research Council and by the Ministry of Petroleum and Energy (OED) through the Norwegian Water Resources and Energy Directorate (NVE).

Edited by: R. Lasaponara

Reviewed by: D. Gauthier, A. Lanorte, and one anonymous referee

\section{References}

Armstrong, R. L. and Armstrong, B. R.: Snow and avalanche climates of the western United States: A comparison of maritime, intermountain and continental conditions, Avalanche Formation, Movement and Effects, Proceedings of the Davos Symposium, IAHS Publ. No. 162, 1987. 
Begueri, S.: Validation and Evaluation of Predictive Models in Hazard Assessment and Risk Management, Nat. Hazards, 37, 315329, 2006.

Bellaire, S., Jamieson, J. B., and Fierz, C.: Forcing the snowcover model SNOWPACK with forecasted weather data, The Cryosphere, 5, 1115-1125, doi:10.5194/tc-5-1115-2011, 2011.

Bellian, J. A., Kerans, C., and Jennette, D. C.: Digital outcrop models: applications of terrestrial scanning LiDAR technology in stratigraphic modelling, J. Sediment. Res., 2, 166-176, 2005.

Benz, U. C., Hofmann, P., Willhauck, G., Lingenfelder, I., and Heynen, M.: Multi-resolution, object-oriented fuzzy analysis of remote sensing data for GIS-ready information, ISPRS J. Photogramm. Remote Sens., 58, 239-258, 2004.

Brivio, P. A., Colombo, R., Maggi, M., and Tomasoni, R.: Integration of remote sensing data and GIS for accurate mapping of flooded areas, Int. J. Remote Sens., 23, 429-441, 2002.

Bühler, Y. A., Kellenberger, T. W., Small, D., and Itten, K. I.: Rapid mapping with remote sensing data during flooding 2005 in Switzerland by object-based methods - a case study, in: Geo Environment and Landscape Evolution II, edited by: Martin-Duque, J. F., Brebbia, C. A., Emmanouloudis, D. E., and Mander, U., WIT Press, 391-400, 2006.

Bühler, Y., Hüni, A., Christen, M., Meister, R., and Kellenberger, T.: Automated detection and mapping of avalanche deposits using airborne optical remote sensing data, Cold Reg. Sci. Technol., 57, 99-106, 2009.

Bühler, Y., Christen, M., Kowalski, J., and Barlet, P.: Sensitivity of snow avalanche simulations to digital elevation model quality and resolution, Ann. Glaciol., 52, 72-80, 2011.

Bühler, Y., Marty, M., and Ginzler, Ch.: High resolution DEM generation in high-alpine terrain using airborne remote sensing techniques, Transactions in GIS, doi:10.1111/j.14679671.2012.01331.x, 2012. 2012.

Christen, M., Kowalski, J., and Bartelt, P.: RAMMS: Numerical simulation of dense snow avalanches in three-dimensional terrain, Cold Reg. Sci. Technol., 63, 1-14, 2010.

Cleve, C., Kelly, M., Kearns, F. R., and Morltz, M.: Classification of the wildland - urban interface: A comparison of pixel- and object-based classifications using high-resolution aerial photography, Comput. Environ. Urban Syst., 32, 317-326, 2008.

Congalton, R. and Green, K.: Assessing the Accuracy of Remotely Sensed Data: Principles and Practices, Lewis Publishers, California, USA, 1999.

Definiens: eCognition Developer. Ver. 8, Munich, Germany, 2011.

DigitalGlobe: QuickBird. Longmont, Co., USA, 2000.

Fischer, L., Eisenbeiss, H., Kääb, A., Huggel, C., and Häberli, W.: Monitoring topographic changes in a periglacial high-mountain face using high-resolution DTMs, Monte Rosa East Face, Italian Alps, Permafrost Periglac. Process., 22, 140-152, 2011.

Frauenfelder, R., Kronholm, K., Solberg, R., Øyen Larsen, S., Salberg, A.-B., Larsen, J. O., and Bjordal, H.: avalRS: Remotesensing derived avalanche inventory data for decision support and hind-cast after avalanche events, Proceedings of the ESA Living Planet Symposium, Bergen, Norway: Contribution no. 147-D4, 2010.

Foody, G. M.: Status of land cover classification accuracy assessment, Remote Sens. Environ., 80, 185-201, 2002.

Gubler, H. and Bader, H. P.: A model of initial failure in slabavalanche release, Ann. Glaciol, 13, 90-95, 1989.
Hall-Beyer, M.: GLCM tutorial home page, http://www.fp.ucalgary. ca/mhallbey/tutorial.htm, 2007.

Haralick, R., Shanmugam, K., and Dinstein, I.: Textural features for image classification, Systems, Man and Cybernetics, IEEE Transactions, 3, 610-621, 1973.

Haralick, R. M.: Statistical and Structural Approaches to Texture, Proceedings of the IEEE, 67, 786-804, 1979.

Harvey, S. and Zweifel, B.: New trends of recreational avalanche accidents in Switzerland, in: Proceedings ISSW2008: International Snow Science Workshop, edited by: Campbell, C., Conger, S., and Haegeli, P., Whistler BC, Canada, 21, 27, 900-906, September 2008

Jaedicke, C., Solheim, A., Blikra, L. H., Stalsberg, K., Sorteberg, A., Aaheim, A., Kronholm, K., Vikhamar-Schuler, D., Isaksen, K., Sletten, K., Kristensen, K., Barstad, I., Melchiorre, C., Høydal, Ø. A., and Mestl, H.: Spatial and temporal variations of Norwegian geohazards in a changing climate, the GeoExtreme Project, Nat. Hazards Earth Syst. Sci., 8, 893-904, doi:10.5194/nhess-8-893-2008, 2008.

Jamieson, B., Haegeli, P., and Gauthier, D.: Avalanche Accidents in Canada, 5, 1996-2007, Canadian Avalanche Association, Revelstoke, BC, Canada, 2011.

Keiler, M., Sailer, R., Jörg, P., Weber, C., Fuchs, S., Zischg, A., and Sauermoser, S.: Avalanche risk assessment - a multi-temporal approach, results from Galtür, Austria, Nat. Hazards Earth Syst. Sci., 6, 637-651, doi:10.5194/nhess-6-637-2006, 2006.

Larsen, S.Ø., Salberg, A.-B., and Solberg, R.: Automatic detection of avalanches in high-resolution optical satellite data, Results from the ESA aval-RS project's feasibility study on automated avalanche detection, Norwegian Computing Center, Internal report no. SAMBA/04/10, 36 pp., 29 January 2010.

Lato, M., Diederichs, M. S., Hutchinson, D. J., and Harrap, R.: Evaluating roadside rockmasses for rockfall hazards using LiDAR data: optimizing data collection and processing protocols, Nat. Hazards, 60, 831-864, 2012.

Leica: Leica ADS40 2nd Generation Airborne Digital Sensor, Leica Geosystems, 2008.

Mantovani, R., Soeters, R., and van Western, C. J.: Remote sensing techniques for landslide studies and hazard zonation in Europe, Geomorphology, 15, 213-225, 1996.

McClung, D. and Schaerer, P.: The Avalanche Handbook, The Mountaineers, Seattle Washington, USA, 1993.

McKean, J. and Roering, J.: Objective landslide detection and surface morphology mapping using high resolution airborne laser altimetry, Geomorphology, 57, 331-351, 2004.

Partio, M. B., Cramariuc, M., and Gabbouj, V. A.: Rock Texture Retrieval Using Gray Level Co-occurrence Matrix, Proc. of 5th Nordic Signal Processing Symposium, October 2002.

Perissin, D. and Wang, T.: Time-Series InSAR Applications Over Urban Areas in China, IEEE J. Selected Topics Appl. Earth Observation Remote Sens., 92-100, 2010.

Salberg, A. B., Larsen, S.Ø., Frauenfelder, R., and Solberg, R.: Automatic detection of avalanches in high resolution optical satellite data, Abstract, Nordic Remote Sensing Days, Troms $\varnothing, 31$ August 2011, Contribution No. CR.2.5, 2011.

Sampl, P. and Zwinger, T.: Avalanche simulation with SAMOS, Ann. Glaciol., 2004, 38, 393-398, 2004.

Sanders, B. F.: Evaluation of on-line DEMs for flood inundation modelling, Adv. Water Res., 30, 1831-1843, 2007. 
Schweizer, J.: Snow avalanche formation and dynamics, Cold Reg. Sci. Technol., 51, 153-154, 2008.

Scott, D.: Avalanche mapping: GIS for avalanche studies and snow science, The Avalanche Review, 27, 20-21, 2009.

Willhauck, G.: Comparison of object oriented classification techniques and standard image analysis for the use of change detection between SPOT multispectral satellite images and aerial photos, in: ISPRS, XXXIII, Amsterdam, 8 pp., 2000.
Yam, G.: Pixel based and object-oriented image analysis for coal fire research, Masters of Science, International Institute for Geo-Information Science and Earth Observation Enschede, The Netherlands, 2003. 